\title{
Campath induction is associated with equalization of short term outcomes in renal retransplantion (but long-term
} outcomes are worse)

\author{
Andrew Kostiuk ${ }^{1}$, Emre Eren ${ }^{1}$, Graham Mitro ${ }^{1}$, Michael Rees $^{2}$ and Jorge Ortiz ${ }^{3}$ \\ ${ }^{1}$ College of Medicine and Health Sciences, University of Toledo, Toledo, OH, USA \\ ${ }^{2}$ Departments of Urology and Pathology, University of Toledo College of Medicine and Health Sciences, Toledo, OH, USA \\ ${ }^{3}$ Department of Surgery, University of Toledo College of Medicine and Health Sciences, Toledo, OH, USA
}

\begin{abstract}
Introduction: Few studies have evaluated the use of Alemtuzumab (Campath) induction in renal retransplantation (RRT).

Methods: We performed a retrospective analysis of 181 retransplants and 494 primary kidney transplants between 03/2004 and 05/2015. All patients were induced with Campath. We compared patient and graft outcomes.

Results: There was no significant difference in age, gender, or ethnicity. The percentage of recipients over the age of 65 (11.0\% for retransplant vs $20.6 \%$ for primary, $\mathrm{p}=0.005)$ and mean PRA (20.1\% for retransplant vs. 8.6\% primary, p<.01) were significantly different. Donor KDPI was nearly identical (39.8 vs. 39.9, p>0.1). No significant differences were found in 1-, 3-, or 5- year patient survival (retransplant: $96.6 \%, 91.0 \%, 87.7 \%$ versus primary transplant: $95.8 \%, 89.1 \%, 81.9 \%$, p $>0.1$ ). For death censored graft survival, only 3 and 5 year marks were significantly different (retransplant: $94.4 \%, 83.7 \%, 77.4 \%$ vs. primary transplant: $95.5 \%$, 91.6\%, 88.4\%, $\mathrm{p}=.008$ and .002 for 3 and 5 years respectively). Graft rejection was measured at 1-, 3-, and 5- year periods (retransplant: $22.3 \%, 28.4 \%$, 32.9\% vs. primary transplant: $20.4 \%, 20.9 \%, 23.5 \%)$ with the only significant difference at 5 years ( $p<.05)$. Delayed graft function rates were not significant $(7.8 \%$ vs. $10.4 \%$, $p>0.1)$. A combination of high PRA and retransplant status was associated with the highest risk of rejection (35.7\%).
\end{abstract}

Conclusion: Despite high rejection rates overall, our results demonstrate acceptable short term outcomes with Campath as an induction agent for kidney retransplantation.

\section{Introduction}

Campath-1H (Alemtuzumab) is a humanized monoclonal antibody that targets the CD52 glycoprotein on lymphocytes and rapidly depletes $\mathrm{T}$ and $\mathrm{B}$ cells. Its use for renal transplantation began in 1998 [1,2]. It is now regularly employed as an off-label induction agent [3]. As part of a steroid-free or reduced steroid regimen, Campath can mitigate the negative side effects of steroid use on kidney transplants [4-6]. Campath induction may potentially expand the use of highrisk, extended-criteria donors and improve outcomes with African Americans, who traditionally fare significantly worse when receiving renal grafts $[7,8]$.

Renal retransplantation (RRT) is a subgroup of recipients who generally experience inferior outcomes. $14.3 \%$ of the transplant waitlist is comprised of patients awaiting RRT and $11.5 \%$ of all kidney transplants from 2013 were retransplants [9]. RRT patients experience increased incidences of rejection and reduced graft survival compared to primary transplant $[10,11]$. This diminished success rate is correlated to both the time to retransplant after primary allograft failure and previous graft survival time [12,13]. Despite the increased risk associated with RRT, it has established itself as a superior option compared to remaining on dialysis $[10,14,15]$.

Numerous reports have described encouraging recipient outcomes with Campath induction therapy in renal transplantation, but few report its efficacy in retransplantation [16]. In this manuscript, we compare the outcomes of retransplant and primary transplant patients who underwent induction therapy with Campath. We surmised that Campath would be efficacious, at least in the short term.

\section{Materials and methods}

We performed a retrospective analysis on a database of 181 retransplant patients and 494 primary kidney transplant patients induced with Campath at the University of Toledo Medical Center in Toledo, Ohio between March 2004 and May 2015. Donor and recipient information was requested from UNOS and all patient data was collected and analyzed retrospectively using Transchart electronic medical records software. This project was approved by the Institutional Review Board at the University of Toledo Medical Center (IRB 200640).

Donor information included type of donor (living or deceased), age, gender, ethnicity, cause of death, history of diabetes and hypertension, donor criteria (extended or standard), and KDPI.

Correspondence to: Andrew Kostiuk, 2510 W Village Dr. Toledo OH 43614, 330-323-9252, USA, E-mail: Drew.Kostiuk@rockets.utoledo.edu

Key words: Campath, kidney, retransplant, single-center

Received: August 10, 2017; Accepted: September 11, 2017; Published: September 14, 2017 
Recipients' information included: age, gender, ethnicity, delayed graft function, history of diabetes and hypertension, graft rejection, date of rejection, and 1-, 3-, and 5-year graft (death censored) and patient survival rates (FIgure 1).

All patients received an immunosuppression induction regimen of methylprednisone $500 \mathrm{mg}$ intravenously (IV) (Solu-Medrol, Pfizer, New York, NY) and Campath (Alemtuzumab $30 \mathrm{mg}$ IV [or .5 mg/kg if less than $60 \mathrm{~kg}]$ ).

Postoperative steroid taper consisted of: methylprednisolone 250 mg IV post-operative day (POD) 1, methylprednisolone $125 \mathrm{mg}$ IV POD 2, prednisone $60 \mathrm{mg}$ PO POD 3, prednisone $40 \mathrm{mg}$ PO POD 4, and prednisone $20 \mathrm{mg}$ PO POD 5.

Tacrolimus $1.5 \mathrm{mg}$ (Prograf, Astellas Pharma, Tokyo, Japan) PO BID and mycophenolate sodium (Myfortic Novartis Pharmaceuticals, Basel, Switzerland or Cellcept, Genentech, San Francisco, CA) 540 mg PO BID were both started POD 1. Tacrolimus levels were measured and titrated to the correct dose. Side effects permitting, mycophenolate sodium was increased to $720 \mathrm{mg}$ PO at discharge. Steroids were generally tapered to off by one month

Antimicrobial prophylaxis was started post-operatively with sulfamethoxazole (800 mg)-trimethoprim (160 mg) 1 tab PO (Bactrim DS, AR Scientific, Philadelphia, PA) 3 times per week and clotrimazole troche $10 \mathrm{mg}$ dissolved in the mouth 4 times per day following oral care. valgancyclovir $450 \mathrm{mg}$ PO (Valcyte, Hoffman-La Roche, Basel, Switzerland) was prescribed based on established risk factors.

Statistical analysis was performed using SPSS 21.0 (IBM, Armonk, New York). Continuous variables assessed with t-tests or MannWhitney $\mathrm{U}$ when appropriate. Categorical variables assessed using Pearson's Chi-square test. Survival analysis was performed using the $\log$ rank method. P-values of less than 0.05 were considered significant.

\section{Results}

\section{Pre-campath era}

598 patients from 1996-2004 (179 RRT and 447 primary transplant, or PTX) were included as part of pre-Campath data. Within this section, patient survival for RRT was $96.6 \%, 94.9 \%$, and $87.7 \%$ for 1-, 3-, 5-year intervals compared to $94.4 \%, 91.9 \%$, and $80.8 \%$ for PTX. Death censored graft survival for RRT was $90.5 \%, 84.9 \%$, and $75.4 \%$ (1-, 3-, 5- years) vs. 95.3\%, 93.9\%, and $88.1 \%$ for PTX. Mean PRA was 17.2 for RRT vs. 12.3 for PTX (FIgure 2).

\section{Campath study donor and recipient characteristics}

A total of 675 patients underwent kidney transplantation with Campath induction. 181 were retransplant (RRT) and 494 primary transplant (PTX). Mean recipient age was 51.2 years for RRT and 52.6 years for PTX. Significantly fewer RRT patients were $>65$ years of age compared to PTX ( 11.0 vs $20.6 \%, \mathrm{p}=0.005$ ). RRT and PTX populations were 59.7\% (108 patients) and 65\% (321 patients) male. Notable differences in racial characteristics of recipients included percentage of Hispanic patients (5.9\% of RRT vs $1.1 \%$ of PTX $\mathrm{p}=.006$ ) and white patients (80.1\% RRT vs 67.6\% PTX, $\mathrm{p}=0.002)$. An increased mean PRA $(20.1 \%$ vs. $8.6 \%, \mathrm{p}=0)$ and PRA $>20 \%$ ( 31.1 vs $14.1 \%, \mathrm{p}<0.001)$ was seen in the RRT group. CMV+ was similar (61.3 vs $58.0 \%$ ) (Table 1). KDPI of donors was comparable (39.8 RTX vs 39.9 PTX). The number of deceased donor kidneys and extended criteria donors (ECD) were similar ( $\mathrm{p}=0.429$ and 0.158$)$. Of the reasons for transplant, only diabetes mellitus was significantly different. $(\mathrm{p}<0.05)$ (Table 2 and FIgure 3 ).

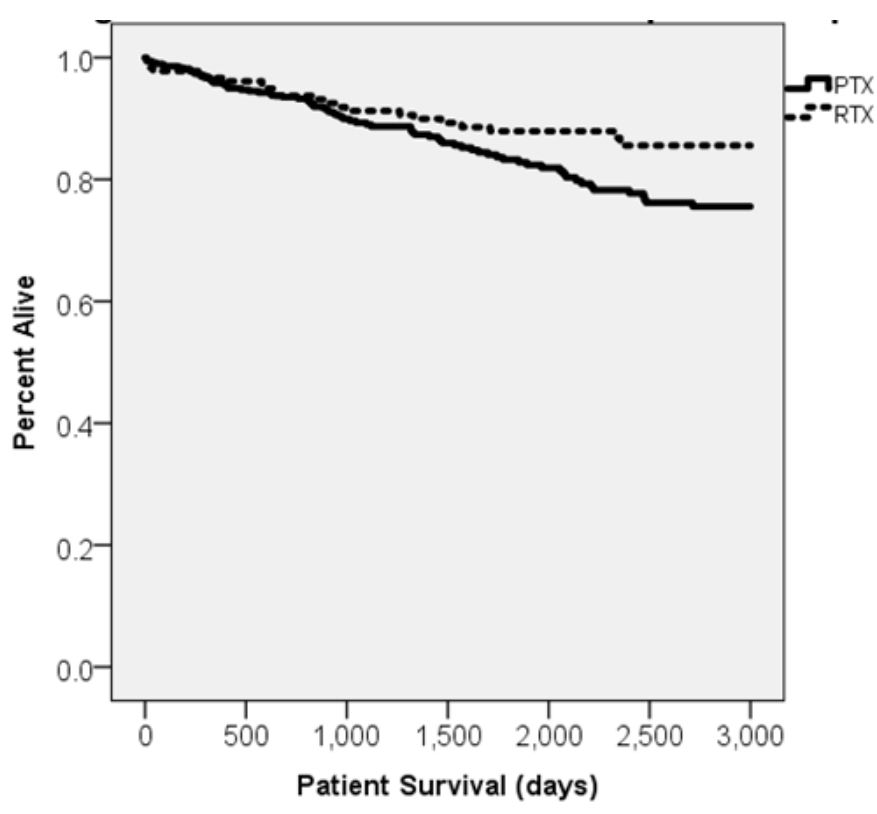

Figure 1. Kaplan-Meier curve displaying patient survival following Campath induction over time.

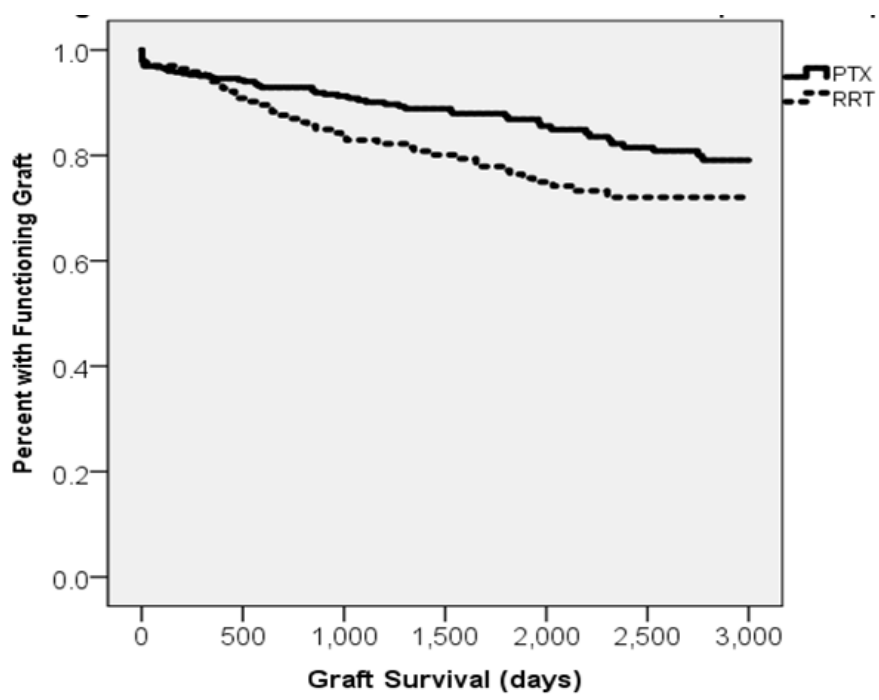

Figure 2. Kaplan-Meier curve displaying death-censored graft survival for RRT vs PTX.

\section{Patient survival}

Patient survival at 1, 3, and 5 years for RRT was $96.7 \%, 91.2 \%$, and $87.9 \%$ respectively compared to $95.8 \%, 89.3 \%$, and $83.3 \%$ for PTX (Table 3) with no statistically significant difference ( $\mathrm{p}=0.639,0.505$, and 0.215 ). Cox survival analysis indicated RRT was non-significantly protective in univariate analysis (HR 0.60, CI 0.376-0.971, p >.05) and not relevant to the final model (Table 4). All causes of patient death studied were similar. (Table 5).

\section{Graft survival and delayed graft function}

1 -, 3-, and 5-year death censored graft survival rates were $94.4 \%$, $83.7 \%$, and $77.4 \%$ for RRT versus $95.5 \%, 91.6 \%$, and $88.4 \%$ PTX ( $\mathrm{p}=0.67,0.008$, and 0.002$)$ (Table 6). RRT status was a risk for graft loss on univariate analysis (HR 1.63, CI 1.987-2.454, p=0.018) but the effect did not remain in the final model (HR 1.49, CI 0.881-2.379, $\mathrm{p}=0.144$ ) 
Table 1. Recipient information.

\begin{tabular}{|c|c|c|c|}
\hline Factor & RRT & PTX & Significance \\
\hline Mean age & 51.2 & 52.6 & 0.256 \\
\hline Elderly $(>65)$ & $108(11.0 \%)$ & $321(20.6 \%)$ & $\mathbf{0 . 0 0 5}$ \\
\hline Sex (male) & $108(59.7 \%)$ & $321(65.0 \%)$ & 0.208 \\
\hline White & $145(80.1 \%)$ & $334(67.6 \%)$ & $\mathbf{0 . 0 0 2}$ \\
\hline Black & $33(18.2 \%)$ & $119(24.1 \%)$ & 0.119 \\
\hline Hispanic & $2(1.1 \%)$ & $29(5.9 \%)$ & $\mathbf{0 . 0 0 6}$ \\
\hline Asian & $1(0.6 \%)$ & $12(2.4 \%)$ & 0.202 \\
\hline Mean PRA & 20.1 & 8.6 & $\mathbf{p}<\mathbf{0 . 0 0 1}$ \\
\hline PRA $>20 \%$ & $56(31.1 \%)$ & $69(14.1 \%)$ & $\mathbf{p}<\mathbf{0 . 0 0 1}$ \\
\hline CMV+ & $61.3 \%$ & $58.0 \%$ & 0.479 \\
\hline
\end{tabular}

Table 2. Donor information.

\begin{tabular}{|c|c|c|c|}
\hline Factor & RRT & PTX & Significance \\
\hline Mean KDPI & 39.8 & 39.9 & 0.777 \\
\hline Related donation & $23(14.8 \%)$ & $61(19.7 \%)$ & 0.25 \\
\hline Cadaveric donation & $130(71.8 \%)$ & $370(74.9 \%)$ & 0.429 \\
\hline ECD status & $20(15.3 \%)$ & $39(10.6 \%)$ & 0.158 \\
\hline DCD & $12(10.2 \%)$ & $37(10 \%)$ & 0.865 \\
\hline Donor race mismatch & $42(23.2 \%)$ & $75(36.4 \%)$ & $\mathbf{0 . 0 0 1}$ \\
\hline CIT (minutes) & 8.04 & 7.56 & 0.188 \\
\hline
\end{tabular}

Table 3. Patient survival.

\begin{tabular}{|c|c|c|c|}
\hline Period & RRT & PTX & Significance \\
\hline Overall & $87.8 \%$ & $83.4 \%$ & 0.186 \\
\hline - 1 year & $173(96.7 \%)$ & $438(95.8 \%)$ & 0.639 \\
\hline - 3 year & $141(91.2 \%)$ & $286(89.3 \%)$ & 0.505 \\
\hline - 5 year & $128(87.9 \%)$ & $204(83.3 \%)$ & 0.215 \\
\hline
\end{tabular}

Table 4. Survival analysis for patient survival.

\begin{tabular}{|c|c|c|c|}
\hline Factor & HR & $\mathbf{9 5 \%}$ CI & Sig. \\
\hline Retransplant & 0.831 & 0.481 & 0.505 \\
\hline $\begin{array}{c}\text { Age at } \\
\text { Transplantation }\end{array}$ & 1.037 & 1.015 & $\mathbf{0 . 0 0 1}$ \\
\hline Male Sex & 1.706 & 0.994 & 0.053 \\
\hline Hispanic Race & 2.848 & 1.293 & $\mathbf{0 . 0 0 9}$ \\
\hline KDPI & 1.013 & 1.004 & $\mathbf{0 . 0 0 4}$ \\
\hline
\end{tabular}

Table 5. Cause of death.

\begin{tabular}{|c|c|c|c|}
\hline Factor & RRT & PTX & Significance \\
\hline Cardiovascular & $38.1 \%$ & $27.5 \%$ & $\mathrm{p}>0.05$ \\
\hline Cancer & $4.8 \%$ & $18.8 \%$ & $\mathrm{p}>0.05$ \\
\hline Infection & $14.3 \%$ & $15.0 \%$ & $\mathrm{p}>0.05$ \\
\hline Other & $42.9 \%$ & $38.8 \%$ & $\mathrm{p}>0.05$ \\
\hline
\end{tabular}

Table 6. Death-censored graft survival.

\begin{tabular}{|c|c|c|c|}
\hline Period & RRT & PTX & Significance \\
\hline Overall & $77.3 \%$ & $88.9 \%$ & $\mathbf{p}<\mathbf{0 . 0 0 1}$ \\
\hline-1 year & $169(94.4 \%)$ & $435(95.5 \%)$ & 0.689 \\
\hline-3 year & $133(83.7 \%)$ & $292(91.6 \%)$ & $\mathbf{0 . 0 0 8}$ \\
\hline-5 year & $117(77.4 \%)$ & $204(88.4 \%)$ & $\mathbf{0 . 0 0 2}$ \\
\hline
\end{tabular}

(Table 7). Delayed graft function (DGF) was comparable at $7.8 \%$ vs. $10.4 \%, \mathrm{p}>0.1)$

\section{Cause of graft failure}

Significant differences in causes of graft failure between RRT and PTX respectively were chronic rejection $(22.2 \%$ vs $7.5 \%, \mathrm{p}<.05)$, allograft complication $(11.1 \%$ vs $3.3 \%, \mathrm{p}<.05)$ and death $(24.1 \%$ vs $54.2 \%, \mathrm{p}<.05$ ) (Table 8 ). Acute rejection, recurrent disease, and primary nonfunction were similar. $(\mathrm{p}>0.05)$ (Table 8$)$.

\section{Discussion}

Retransplantation remains the most effective treatment of end stage renal disease for those who have experienced the loss of an initial graft $[11,17,18]$. The percentage of retransplants performed has increased to $15 \%$ in 2016 [19]. Patient survival among recipients for initial and second transplants has become comparable over the years $[11,20]$. Our analysis yielded no significant difference between RRT and PTX patient survival in 1-, 3-, or 5-year intervals (Table 3). Final multivariate analysis for patient survival did not note being African American as a significant risk factor (as has been commonly reported) but did designate high KDPI, older age at transplant, and Hispanic race as significant risk factors (Table 4) [21,22].

Past RRT evaluations have noted the markedly worse outcomes in retransplant graft survival in comparison to what one might expect in primary transplants $[10,20,23-25]$. Recently, Khalil et al. found that RRT graft survival approached PTX 1-, 3-, 5-, and 10-year graft survival, but were still significantly inferior [11]. Our 1-, 3-, and 5-year death censored graft survival rates in RRT $(94.4 \%, 83.7 \%, 77.4 \%)$ and PTX $(95.5 \%, 91.6 \%, 88.4 \%)$ groups were significantly different in

Table 7. Multivariate model for death-censored graft survival.

\begin{tabular}{|c|c|c|c|}
\hline Factor & HR & $\mathbf{9 5 \%}$ CI & Sig. \\
\hline Retransplant & 1.551 & $0.954-2.519$ & 0.076 \\
\hline Rejection History & 3.878 & $2.402-6.261$ & $\mathbf{p}<\mathbf{0 . 0 0 1}$ \\
\hline KDPI & 1.02 & $1.011-1.029$ & $\mathbf{p}<\mathbf{0 . 0 0 1}$ \\
\hline PRA $>20 \%$ & 2.174 & $1.31-3.607$ & $\mathbf{0 . 0 0 3}$ \\
\hline
\end{tabular}

Table 8. Cause of graft failure.

\begin{tabular}{|c|c|c|c|}
\hline Factor & RRT & PTX & Significance \\
\hline Acute Rejection & $13.0 \%$ & $15.8 \%$ & $\mathrm{p}>0.05$ \\
\hline Chronic Rejection & $22.2 \%$ & $7.5 \%$ & $\mathbf{p}<\mathbf{0 . 0 5}$ \\
\hline $\begin{array}{c}\text { Allograft } \\
\text { Complication }\end{array}$ & $11.1 \%$ & $3.3 \%$ & $\mathbf{p}<\mathbf{0 . 0 5}$ \\
\hline Death & $24.1 \%$ & $54.2 \%$ & $\mathbf{p}<\mathbf{0 . 0 5}$ \\
\hline Recurrent Disease & $3.7 \%$ & $5.8 \%$ & $\mathrm{p}>0.05$ \\
\hline $\begin{array}{c}\text { Primary Non- } \\
\text { Function }\end{array}$ & $1.9 \%$ & $5.0 \%$ & $\mathrm{p}>0.05$ \\
\hline Other & $24.1 \%$ & $8.3 \%$ & $\mathbf{p}<\mathbf{0 . 0 5}$ \\
\hline
\end{tabular}

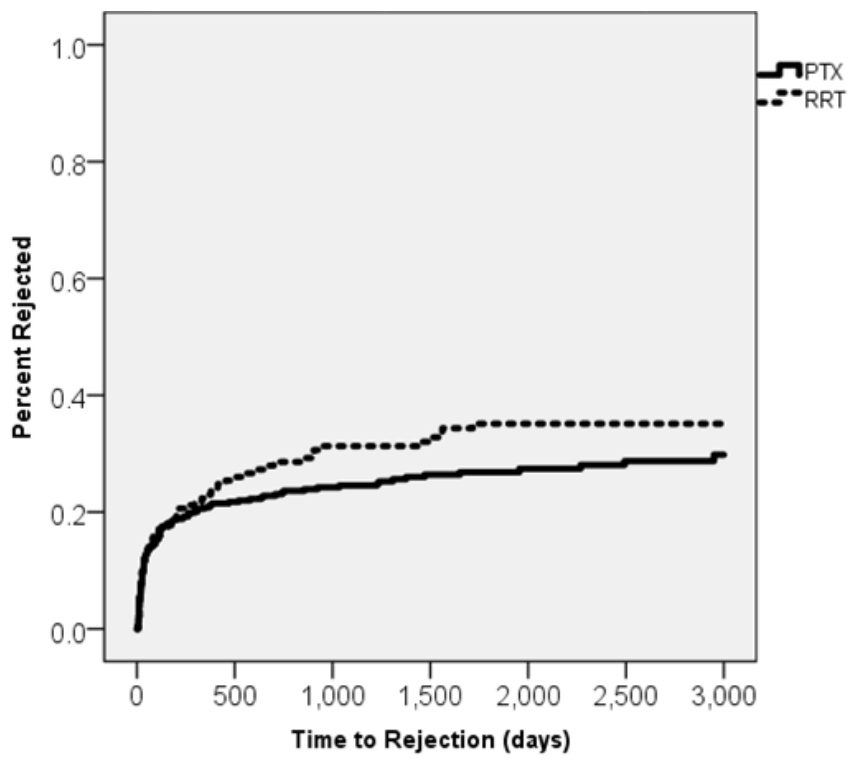

Figure 3. Kaplan-Meier curve displaying rejection following Campath induction over time. 
only the 3 and 5 year categories ( $\mathrm{p}=.008$ and .002 respectively). On multivariate analysis, we found rejection history, and PRA $>20 \%$ as the most significant risk factors for inferior graft outcomes (Table 7). Being that there is no significant difference between graft survival over a 1 year period, we believe this lends credence to the notion that Campath will be efficacious in narrowing the disparities between RTX and PTX in the short term.

When examining causes of graft failure, death and chronic rejection were the most common in RRT and death was most prominent in the PTX group. Other publications examining RRT have cited rejection, surgical complications, chronic allograft nephropathy, chronic glomerulonephritis, and hypertensive nephropathy as common causes of graft failure [10,21,26,27].

While we discovered chronic rejection to be significantly more common in RRT versus PTX ( $\mathrm{p}<.05)$, no significant difference existed in overall acute rejection. This conforms with the findings of Dunn et al. but differs from Heaphy et. al., who demonstrated that retransplant recipients were more likely to be treated for acute rejection $[13,28]$. Our data shows no significant difference in rejection based upon 1, 3, and 5 year intervals (RRT: $22.7 \%, 30.9 \%, 34.7 \%$ vs PTX: $20.9 \%, 24.4 \%$, $26.7 \%, \mathrm{p}=.654, .163$, and .115 respectively). Ingsathit et al., reported rejection rates of $16.6 \%$ while Ahmed et. al noted that patients receiving a second transplant had rejection rates of $8 \%[10,23]$. Similar values were reported elsewhere, indicating our rejection rates are higher than what is typically reported [29-31]. We attributed this increased rejection to the steroid free regimens and low dose MMF. Therefore, we have modified our protocols to induce how dose MMF sooner in those deemed high risk for rejection. Our rejection rates subsequently declined precipitously (data not shown). This reaction has been observed before in studies seeking to utilize Campath in populations with early steroid withdrawal [32].

Elevated PRA is another well documented risk factor for poor outcomes in renal transplantation and retransplantation. Among the patients in our analysis, we found a significantly increased mean PRA (20.1\% vs $8.6 \%)$ in the RRT group as well as a significantly higher incidence of a PRA $>20 \%$ (31.1\% vs. $14.1 \%$ ). Ahmed et. al reported average PRA values of $34.49 \%$ in patients who had received two transplants while other papers reported a significant difference between the two, but did not list individual values $[10,23]$.

Due to the relative risk of rejection that both high PRA and RRT status impose, we also evaluated what combination of these factors posed the greatest overall threat $[13,28]$. Unsurprisingly, the combination of high PRA and retransplant history presented with the highest combined possibility of graft rejection $(35.7 \%)$ when compared to RRT and low PRA, PTX and high PRA, and PTX and low PRA. Therefore, we recommend maintenance steroids and very close followup of these high-risk patients.

The incidence of DGF following a deceased donor kidney transplant are estimated to range between 23 and 50 percent with higher levels reported in RRT compared to PTX [13,18,33,34]. We did not observe a significant difference in DGF between RRT and PTX in our investigation $(10.4 \%$ vs. $7.8 \% \mathrm{p}=.376)$. Additionally, the number of our patients experiencing DGF is $10-15 \%$ lower in both categories than other studies examining retransplantation [20,35]. This implies Campath may be more effective than non-depleting antibody agents in mitigating unknown donor and transplant center characteristics that contribute to DGF [33-35]. This might also reflect utilization of higher quality organs in patients transplanted at our center. Mean KDPI for
RRT group was $39.8 \%$ and not significantly different from PTX. The utilization of high KDPI (>75) was $16.9 \%$ for RRT and $12.7 \%$ for PTX $(\mathrm{p}=.238)$. While mean KDPI is a commonly reported statistic, frequency of high KDPI ( $>75)$ is not often disclosed in the literature. Prevalence of ECD kidneys was $15.3 \%$ for RRT and $10.3 \%$ for PTX ( $\mathrm{p}=.158$ ). Louvar et al. reported ECD kidneys comprising a similar proportion of their donors [35]. Further, over 70\% of our patients in both cohorts received deceased donor kidneys (Table 2).

Before the introduction of Campath at our facility, patient survival for RRT was $96.6 \%, 94.9 \%$, and $87.7 \%$ for 1-, 3-, 5- year intervals compared to $94.4 \%, 91.9 \%$, and $80.8 \%$ for PTX. Death censored graft survival for RRT was $90.5 \%, 84.9 \%$, and $75.4 \%$ (1-, 3-, 5- years) vs. 95.3\%, 93.9\%, and $88.1 \%$ for PTX. This represents acceptable RRT results predating the addition of Campath, which ideally reflects a sound protocol. However, the pre-Campath outcomes were not evaluated in this investigation as the data and demographic collections were not part of our updated database and would have suffered from significant error effects.

Our analysis possesses numerous strengths. The relatively large sample size, single-center focus, long-term follow-up, and a consistent protocol eliminate uncertainty caused by hidden variables. Furthermore, ours is the only examination to focus solely on the utilization of Campath as an induction agent in renal retransplantation.

There are some limitations to our study as well. The retrospective nature allows for confounding variables that may affect the strength of our results. Additionally, because we performed a single center analysis, results may not apply to all centers. We were limited in analysis by relatively small proportions of certain ethnic groups. No other induction methodology was used as a control group. Finally, inconsistencies in data collection limited our pre-Campath comparison.

\section{Conclusion}

The uses of Campath as an induction therapy for primary renal transplant have been well documented and produced positive findings [16]. We believe that its use extends to retransplant procedures as we have found acceptable outcomes within that population. There is no significant difference in patient survival between RRT and PTX reflecting the recent trend $[11,20]$. Though there were some significant differences in graft survival rates, Campath was shown to be effective in equalizing graft survival in the short term. The overall short term equalization eventually "wears off" and the negative outcomes begin to present in at risk populations like RRT patients. Additionally, although rejection levels in this study were higher than what might be found elsewhere, this is largely resulting from the steroid free protocol administered to patients and has no reflection on the efficacy of Campath to generate positive outcomes as continued steroid maintenance resulted in a subsequent decline in rejection rates. Therefore, we advise steroids and close follow up in high risk recipients even if they are out a long time. Based on all the findings in this project, we encourage routine usage of Campath versus other induction agents in retransplant patients as it can help shield this population from the inherent risk of rejection that they possess. However, these patients need close observation in the long term as outcomes are significantly inferior. If an institution is unable to provide the long term surveillance required, other induction therapies should be considered.

Contributions: Kostiuk, A.: Wrote the paper; Eren, E.: Wrote the paper; Mitro, G.: Statistical analysis and wrote the paper; Rees, M.: reviewed the paper; Ortiz, J.: designed the study, reviewed and edited the paper 


\section{Funding}

None to disclose

\section{Conflicts of interest}

None to disclose

\section{References}

1. Hale G, Xia MQ, Tighe HP, Dyer MJ, Waldmann H (1990) The CAMPATH-1 antigen (CDw52). Tissue Antigens 35: 118-127. [Crossref]

2. Calne R, Friend P, Moffatt S (1998) Prope tolerance, perioperative campath $1 \mathrm{H}$, and low-dose cyclosporin monotherapy in renal allograft recipients. Lancet (London, England). 351(9117):1701-1702

3. Pham PTT, Lipshutz GS, Pham PTT, Kawahji J, Singer JS, et al. (2009) The evolving role of alemtuzumab (Campath-1H) in renal transplantation. Drug Des Devel Ther : $41-49$.

4. Tan HP, Donaldson J, Basu A (2009) Two hundred living donor kidney transplantations under alemtuzumab induction and tacrolimus monotherapy: 3-Year follow-up. Am J Transplant 9: 355-366.

5. Knechtle SJ, Fernandez LA, Pirsch JD, Becker BN, Chin LT, et al. (2004) Campath-1H in renal transplantation: The University of Wisconsin experience. Surgery 136: 754760. [Crossref]

6. Ciancio G, Burke GW, Gaynor JJ (2005) A randomized trial of three renal transplant induction antibodies: early comparison of tacrolimus, mycophenolate mofetil, and steroid dosing, and newer immune-monitoring. Transplantation 80: 457-465

7. Shin M, Song SH, Kim JM (2011) Alemtuzumab induction in deceased donor kidney transplantation. Transplant Proc 43: 2365-2378.

8. Smith AA, John MM, Dortonne IS (2015) Racial Disparity in Renal Transplantation: Alemtuzumab the Great Equalizer? Ann Surg 262: 669-674.

9. Matas AJ, Smith JM, Skeans MA, Thompson B, Gustafson SK, et al. (2015) OPTN/ SRTR 2013 Annual Data Report: kidney. Am J Transplant 15 Suppl 2: 1-34. [Crossref]

10. Ahmed K, Ahmad N, Khan MS, Koffman G, Calder F, et al. (2008) Influence of number of retransplants on renal graft outcome. Transplant Proc 40: 1349-1352. [Crossref]

11. Khalil AK, Slaven J, Mujtaba MA (2016) Re-transplants compared to Primary Kidney Transplants Recipients: A Mate Kidney Paired analysis of the OPTN/UNOS database. Clin Transplant

12. El-Agroudy AE, Wafa EW, Bakr MA, Donia AF, Ismail AM, et al. (2004) Living-donor kidney retransplantation: risk factors and outcome. BJU Int 94: 369-373. [Crossref]

13. Heaphy ELG, Poggio ED, Flechner SM (2014) Risk factors for retransplant kidney recipients: Relisting and outcomes from patients' primary transplant. Am J Transplan 14: $1356-1367$.

14. Gjertson DW (2016) A multi-factor analysis of kidney regraft outcomes. Clin Transp 2002: 335-349. [Crossref]

15. Rao PS, Schaubel DE, Wei G, Fenton SSA (2006) Evaluating the survival benefit of kidney retransplantation. Transplantation 82: 669-674.

16. Schold J, Poggio E, Goldfarb D, Kayler L, Flechner S (2015) Clinical outcomes associated with induction regimens among retransplant kidney recipients in the United States. Transplantation 99: 1165-1171.

17. Horovitz D, Caumartin Y, Warren J (2009) Outcome of third renal allograft retransplants versus primary trans-plants from paired donors. Transplantation 87: 1214
18. Ojo A, Wolfe RA, Agodoa LY (1998) Prognosis after primary renal transplant failure and the beneficial effects of repeat transplantation: multivariate analyses from the United States Renal Data System. Transplantation 66: 1651.

19. OPTN. Current U.S. Waiting List. Available at: http:// optn.transplant.hrsa.gov/ latestData/rptData.asp.

20. Pour-Reza-Gholi F, Nafar M, Saeedinia A (2005) Kidney retransplantation in comparison with first kidney trans-plantation. Transplant Proc 37: 2962.

21. 1998 Annual Report of the US Scientific Registry for Transplant Recipients and the Organ Procurement and Transplantation Network: transplant data: 1988-1997. Richmond, VA: United Network for Organ Sharing

22. Young CJ, Gaston RS (2000) Renal transplantation in black Americans. N Engl J Med 343: 1545-1552. [Crossref]

23. Ingsathit A, Kantachubesiri S, Rattanasiri S, Avihingsanon Y, Premasathian N, et al (2013) Long-term Outcome of Kidney Retransplantation in Comparison with First Kidney Transplantation: A Report From the Thai Transplantation Registry.

24. Delmonico FL, Tolkoff-Rubin N, Auchincloss H Jr, Farrell ML, Fitzpatrick DM, et al. (1994) Second renal transplantations. Ethical issues clarified by outcome; outcome enhanced by a reliable crossmatch. Arch Surg 129: 354-360. [Crossref]

25. Etienne T, Goumaz C, Ruedin P, Jeannet M (1992) Renal retransplantation in Switzerland: poor HLA matching of first and subsequent allografts does not appear to affect overall graft survival. Transpl Int 5 Suppl 1: S65-66. [Crossref]

26. Morales JM, Marcén R, del Castillo D (2012) Risk factors for graft loss and mortality after renal transplantation according to recipient age: a prospective multicentre study. Nephrology Dialysis Transplantation 27.

27. Tanabe K, Takahashi K, Toma H (1996) Causes of long-term graft failure in renal transplantation. World J Urol 14: 230-235. [Crossref]

28. Dunn, T.B. et al. (2011) Revisiting traditional risk factors for rejection and graft loss after kidney transplantation. American Journal of Transplantation 11: 2132-2143.

29. Gjertson DW (2003) A multi-factor analysis of kidney regraft outcomes. In: Cecka JM, Terasaki P (Eds.) Clinical transplants 2002. Los Angeles: UCLA Immunogenetics Center, pp. 335-349.

30. Gallichio MH, Hudson S, Young CJ, Diethelm AG, Deierhoi MH. Rena retransplantation at the University of Alabama at Birmingham: Incidence and outcome. In: Cecka JM, Terasaki PI, eds. Clinical transplants. Los Angeles: UCLA Tissue Typing Laboratory, 1998, pp. 169-175.

31. Sampaio M, Chopra B, Sureshkumar K (2016) Outcomes of Depleting Antibody Induction in Kidney Transplantation: A Paired Kidney Analysis. Am J Transplant 16 (suppl 3).

32. Suresh kumar KK, Hussain SM, Thai NL, Ko TY, Nashar K, et al. (2014) Impact of steroid maintenance on the outcomes in first-time deceased donor kidney transplant recipients: Analysis by induction type. World Journal of Transplantation (3):188-195.

33. Traynor C, O'Kelly P, Denton M, Magee C, Conlon PJ (2012) Concordance of outcomes of pairs of kidneys trans-planted into different recipients. Transplant Int 25: 918.

34. Plata-Munoz JJ, Vaidya A, Fuggle SV, Friend PJ (2009) Effect of alemtuzumab or basiliximab induction therapy on graft function and survival of kidneys from donors after cardiac death. Transplant International 1024-1027.

35. Louvar DW, Li N, Snyder J, Peng Y, Kasiske BL, et al. (2009) "Nature versus nurture" study of deceased-donor pairs in kidney transplantation. J Am Soc Nephrol 20: 13511358. [Crossref]

Copyright: (C2017 Kostiuk A. This is an open-access article distributed under the terms of the Creative Commons Attribution License, which permits unrestricted use, distribution, and reproduction in any medium, provided the original author and source are credited. 